\title{
Thought-shape fusion in young healthy females appears after vivid imagination of thin ideals
}

Andrea Wyssen, PhD. ${ }^{\mathrm{a}}$, Jennifer S. Coelho, PhD. ${ }^{\mathrm{b}}$, Peter Wilhelm, PhD. ${ }^{\mathrm{c}}$, Grégoire Zimmermann, PhD. ${ }^{\mathrm{d}}$, \& Simone Munsch, $\mathrm{PhD} .^{\mathrm{e}}{ }^{*}$

a. University of Fribourg, Institute of Psychology, Department of Clinical Psychology and Psychotherapy, Rue de Faucigny 2, 1700 Fribourg, Switzerland, andrea.wyssen@ unifr.ch b. Eating Disorders Program, Douglas University Institute in Mental Health, Verdun, Quebec Department of Psychiatry, McGill University, Montreal, Quebec, Canada, jennifer.coelho@cw.bc.ca

c. University of Fribourg, Institute of Psychology, Department of Clinical Psychology and Psychotherapy, Rue de Faucigny 2, 1700 Fribourg, Switzerland, peter.wilhelm@unifr.ch

d. University of Lausanne, Institute of Psychology, Geopolis, 1015 Lausanne, Switzerland, gregoire.zimmermann@unil.ch

e. University of Fribourg, Institute of Psychology, Department of Clinical Psychology and Psychotherapy, Rue de Faucigny 2, 1700 Fribourg, Switzerland, simone.munsch@unifr.ch

*Correspondence to: Simone Munsch, University of Fribourg, Institute of Psychology, Department of Clinical Psychology and Psychotherapy, Rue de Faucigny 2, 1700 Fribourg, Switzerland, simone.munsch@unifr.ch, Phone: +41 263007657 


\section{Thought-shape fusion in young healthy females appears after vivid imagination of thin}

\section{ideals}

\section{INTRODUCTION}

Mass media provide daily, multiple messages about attractiveness, ideal body weight and shape, self-control, and food and weight management. Trying to achieve an ideal body represents a constant challenge especially for young women. As a consequence, feeling negatively about one's appearance, and having a dysfunctional attitude towards one's body has become a normative discontent (Grogan, 2008; Tiggemann, 2002). Up to $72 \%$ of women in representative population-based samples reported substantial body dissatisfaction (BD) as well as the experience of a self-ideal discrepancy in comparison with thin ideals (Fiske, Fallon, Blissmer, \& Redding, 2014). Results from a large international study corroborated the high frequency of $\mathrm{BD}$ and a drive for thinness in young women and revealed that exposure to different sources of western media predicted the extent of BD and the preference of a very thin beauty ideal (Swami et al., 2010). A meta-analytic overview of cross-sectional studies, assessing media exposure in terms of reading fashion magazines and watching television, implies that media consumption is positively correlated with $\mathrm{BD}$ and dysfunctional eating (Levine \& Murnen, 2009). In their systematic review including cross-sectional, experimental and longitudinal studies, López-Guimerà and colleagues (2010) acknowledged mass media as a risk factor for $\mathrm{BD}$ and disordered eating behavior. Women with more pronounced $\mathrm{BD}$ are particularly vulnerable, since these women tend to be more likely to consume media and to engage in upward social comparison and thus are more prone to experience self-ideal discrepancy. Despite the agreement that thin-ideal exposure is important in the development of $\mathrm{BD}$, a direct association is unlikely and different variables such as preexisting $\mathrm{BD}$ and cognitive processes such as thin-ideal internalization are likely to influence this relationship crucially (Hausenblas et al., 2013; López-Guimerà et al., 2010). In line with this previous 
research, a recent meta-analysis, including 204 experimental, correlational and longitudinal studies, demonstrated that the effect of thin ideals on women's BD and eating disorder (ED) symptomatology is marginal. However, especially when assessed in laboratory studies, women with preexisting BD seemed to experience a stronger negative effect from thin-ideal exposure (Ferguson, 2013).

$\mathrm{BD}$ in young women is related to ED symptomatology. High levels of BD have been described as the strongest predictor of the risk for onset of any ED symptoms: in a prospective study with adolescent girls, $24 \%$ of those with high BD showed symptoms of disordered eating eight years later versus 6\% of those with low BD (Stice, Marti, \& Durant, 2011). Related to possible longer-term consequences of repeated media exposure it has been found that in female adolescents, immediate negative consequences after a short exposure to thin ideal related television commercials predicted BD and drive for thinness two years later (even when controlling for initial BD) (Hargreaves \& Tiggemann, 2003). It may be assumed that the immediate responsiveness to a brief media exposure in the laboratory represents a marker for the susceptibility to the negative influence of thin ideals in media. Cumulative experiences may contribute to a negative body image and further ED symptomatology (Hargreaves \& Tiggemann, 2003).

In certain young women, media exposure leads to the experience of a discrepancy between self and ideal body image (Higgins, 1987) followed by negative emotions, dysfunctional behaviors and depreciative cognitions (Myers \& Crowther, 2009; Tiggemann \& McGill, 2004). This discrepancy is influenced by cognitive factors such as the tendency to internalize thin ideals (Dittmar, Halliwell, \& Stirling, 2009; Dittmar \& Howard, 2004), or the activation of appearance related cognitions (Ridolfi, Myers, Crowther, \& Ciesla, 2011). Cognitive distortions, defined as inaccurate tendencies in information processing, play an important role in the maintenance of mental disorders, e.g., in panic or depressive disorders and also in EDs. As such, weight and shape concerns represent core features of ED pathology 
and a target of evidence-based treatment of EDs (Cooper \& Fairburn, 1992; Fairburn, 1981). In the present study, we hypothesize that exposure to thin ideals will trigger specific bodyrelated cognitive distortions.

The original food-related phenomenon of Thought-Shape Fusion (TSF) was extended from research on the Thought-Action Fusion (TAF) paradigm in individuals with obsessional compulsive disorder (OCD) (Shafran, Thordarson, \& Rachman, 1996), and has been shown to be an important cognitive distortion in EDs (e.g., Coelho, Baeyens, Purdon, Pitet, \& Bouvard, 2012; Coelho, Carter, McFarlane, \& Polivy, 2008; Shafran \& Robinson, 2004; Shafran, Teachman, Kerry, \& Rachman, 1999). The food-related TSF concept includes the irrational belief that merely thinking about eating fattening/forbidden foods leads to a higher probability of weight gain or change in shape (Likelihood TSF), the experience of pronounced feelings of fatness (Feeling TSF), and the perception of moral wrongdoing (Moral TSF). Susceptibility to TSF has been shown to be strongly related to the severity of ED symptomatology and measures of general psychopathology in healthy women (Shafran et al., 1999) and patients with EDs (Shafran \& Robinson, 2004). It has been demonstrated that TSF can be induced by the vivid imagination of fattening/ forbidden foods or weight gain in healthy undergraduate students (Coelho, Roefs, \& Jansen, 2010) and even more in patients with EDs (Coelho, Baeyens, et al., 2012; Coelho et al., 2008).

We hypothesized that it is not only thoughts about consuming food that can induce body-related cognitive distortions, but also exposure to thin ideals and their vivid imagination. We expected that imagining thin ideals will lead to impaired mood, body image satisfaction (BIS) and distorted body-related cognitions, such as perceived weight gain and related behaviors such as the urge to restrict food intake. In other words, we investigated for the first time whether correlates of TSF are activated after a short exposure to a fashion magazine in a waiting room design and the subsequent imagination of the thin ideals. According to recent results (Ferguson, 2013; López-Guimerà et al., 2010) we expected minimal effects of the 
mere exposure to thin ideals in a magazine, but a more pronounced influence of vivid imagination. Concretely, we expected that Thought-Shape Fusion Body (TSF-B) is triggered after vivid imagination of thin ideals, which will be demonstrated by increased feelings of fatness, fear of gaining weight or of moral wrongdoing as well as the urge to restrict food intake. We further assumed that after vivid imagination of thin ideals, mood and BIS will decrease. We adapted the original TSF induction procedure (Radomsky, De Silva, Todd, Treasure, \& Murphy, 2002) and replaced food stimuli by the imagination of female thin ideals. According to the literature (Ferguson, 2013; López-Guimerà et al., 2010), these effects were expected to be more pronounced in individuals characterized by preexisting higher ED symptomatology. In addition we tested whether body mass index (BMI) moderated this effect, since it has been repeatedly demonstrated that a higher BMI in women, negatively influences BIS (e.g., Stice \& Whitenton, 2002).

\section{MATERIAL AND METHODS}

\subsection{Participants}

A total of 91 healthy German-speaking female students were recruited to participate in this study. Recruitment of the participants took place at the University of Fribourg, Switzerland. Inclusion criteria were: age between 18-35 years, availability for participation in the study, and sufficient German language skills. Exclusion criteria were present mental disorders according to the DIPS (Diagnostisches Interview für psychische Störungen; telephone interview, Schneider \& Margraf, 2011), pregnancy, or serious medical conditions affecting eating and mood. No participants had to be excluded. All participants were bachelor or master students at the University of Fribourg in Switzerland, and had at least secondary school level. $39.6 \%$ of the participants were Swiss, $52.7 \%$ were German, and $7.7 \%$ had another nationality.

2.2. Procedure 
This study is part of a multi-center study on the impact of cognitive distortion and media exposure in young healthy women compared to groups of women suffering from EDs or other mental disorders. For a detailed description of the overall study protocol see (Munsch, 2014). Data collection was threefold and included informed consent and assessment of baseline measures (week 1), completion of diagnostic interviews (week 2), and the laboratory assessment (week 3).

Participants were randomly assigned to either the thin-ideal group (i.e., exposure to a fashion magazine representing the thin ideal and subsequent vivid imagination of the female bodies) or the control group (i.e., exposure to a nature magazine and subsequent vivid imagination of landscapes) during the experiment. The experiment was an adapted version of the original waiting room design of Turner and colleagues (1997). At the beginning of the experiment, participants were asked to fill in self-report measures of BIS and mood (pre magazine exposure; $T 1$ ). The participants were guided into a standardized waiting room that consisted of chairs and a table. The participants were asked to wait while physiological measures were taken (not reported in this publication). The experimenter left the waiting room and returned three minutes later with one magazine. Participants were explicitly asked to have a close look at the pictures in the magazine while waiting. The experimenter left the room for another ten minutes. The magazine was either a fashion magazine (spring edition of Vogue, 2/2012, thin-ideal group) or a carefully chosen magazine with neutral stimuli (National Geographic, Collector's Edition 15/2012, control group). We ensured that the control magazine contained as few images as possible picturing people. No other reading materials or pictures were available in the waiting room. After ten minutes, participants were asked to return to the first room and to complete measures of BIS, and mood (post magazine exposure; T2).

Thereafter an 8 -minute nature film ${ }^{1}$ was shown, followed by a third assessment of current BIS and mood (pre imagination; T3). Next, vivid imagination was guided following 
the procedure of Radomsky et al. (2002), Shafran et al. (1999) and Coelho et al. (2008). Participants in the thin-ideal exposure group were asked to remember actively the thin female bodies in the magazine that they considered to be most attractive, and to imagine them in vivid detail for five minutes. In the control group they imagined landscape pictures that they liked most. Participants were then asked to write down the sentence: "I am imagining..." (describing the female body or the landscape respectively they imagined). Afterwards, participants again completed questions about their current BIS and mood (post imagination; T4). In addition, participants completed a questionnaire to assess current body-related cognitive distortions (TSF-B). Finally height and weight were measured. Participants were asked not to disclose the purpose of the study to other participants. The local human ethics committees of the department of psychology of the University of Fribourg as well as of the State of Fribourg approved the study protocol.

\subsection{Measures}

Diagnostic interviews to exclude mental disorders: The DIPS (Diagnostisches Interview für psychische Störungen; Schneider \& Margraf, 2011) is a structured diagnostic interview based on the Diagnostic and Statistical Manual of Mental Disorders (DSM-IV-TR; APA, 2000). The retest-reliability ranges from .35 to .94 (Cohen's kappa) and the interrater reliability from .57 to .92 (Schneider \& Margraf, 2011). The interview was conducted by telephone. The validity of telephone-based interviews is comparable to face-to-face interviews when screening for diagnoses (Rohde, Lewinsohn, \& Seeley, 2014).

Body mass index (BMI): Weight and height were measured on an electronic balance scale (Seca) and by a stadiometer (Seca) with participants wearing clothing without shoes. BMI was calculated as weight in kilograms divided by the square of height in meters $\left(\mathrm{kg} / \mathrm{m}^{2}\right)$.

Eating disorder pathology: The Eating Disorder Examination Questionnaire (EDE-Q; German version by Hilbert \& Tuschen-Caffier, 2006), is a self-report version of the Eating Disorder Examination (EDE; Fairburn, Cooper, \& Shafran, 2003) assessing ED behaviors and 
symptoms during the past 28 days. It consists of 28 items; 22 items address attitudinal aspects of ED pathology. These items are rated on a scale from 0-6 and can be summarized into a global score as well as four subscales: restraint eating, eating concern, shape concern and weight concern. Among six additional items, the frequency of key ED behaviors is assessed. The EDE-Q has good psychometric properties and is suitable to detect symptoms of EDs in individuals of the general population (Mond, Hay, Rodgers, Owen, \& Beumont, 2004). Cronbach's alpha of the German version ranges from .85 to .97 (Hilbert, Tuschen-Caffier, Karwautz, Niederhofer, \& Munsch, 2007). In the present sample the values were between .75 and .91 .

\section{Measures during the experiment: BIS, mood and cognitive distortions:}

The Visual Analog Scale Body Image Satisfaction (VAS-BIS) is a 7-item scale developed to assess the changes in BIS during the experiment (Wyssen \& Munsch, unpublished, available from the authors). Participants rated each item on a 100-mm visual analog scale (VAS) (0 not at all to 100 completely). The scale contains questions such as: "How much are you worrying about your appearance at the moment?" Other items focused on how comfortable the participants feel in their body at the present moment, if they are satisfied with their body shape and weight, and if they have the desire to control or change their body shape. A total score based on the average of the items was obtained. Cronbach's alpha for each of the four measures during the experiment was between .89 and .92 .

The Brief Mood Scale (BMS) is a modified version of a brief three dimensional mood scale that assesses valence, calmness, and energetic arousal with bipolar items and is highly sensitive to capture changes in mood states over time (Wilhelm \& Schoebi, 2007). A version with four items to measure valence and four items to measure calmness was used in this experiment. Responses were given on a 100-mm VAS (0-100). As valence and calmness were highly correlated ( $r \geq .49)$, we collapsed them into a common scale (eight items). Cronbach's alpha was between .88 and .95 . 
The Thought-Shape Fusion Body State Scale (TSF-B state) is a 5-item questionnaire assessing body-related cognitive distortions. The scale was adapted and shortened from the original items employed by Radomsky et al. (2002) and Coelho et al. (2008). Items were back translated between English and German, and adapted to refer to thin-ideal exposure (Wyssen \& Munsch, unpublished). The final scale resulted in five items, assessing participants' responses to the vivid imagination manipulation. The items include ratings of the likelihood of weight gain, the extent of feeling fatter, the urge to restrict food intake, the extent of moral wrongdoing and the desire to reduce the effects of imagining the pictures in the magazine (see appendix A). Participants rated each item on a 100-mm VAS scale (0-100). Cronbach's alpha for this measure was .86 .

\subsection{Statistical analysis}

Data were analyzed with SPSS 22. To first test whether changes in mood and BIS across the experimental session were different for the two experimental groups we computed a two-factorial $(2 * 4)$ repeated measures ANOVA with the within subject factor time of measurement (T1-T4) and the between subject factor experimental condition (control group vs. thin-ideal group).

When the interaction between time and experimental condition was significant, we computed multiple regression models to qualify whether the expected group difference was the result of imagination or whether mere magazine exposure was sufficient. Therefore, we predicted mood after magazine exposure (T2) with mood before magazine exposure (T1) and tested in a second step whether experimental condition (dummy coded: $0=$ control group) explained additional variance. Then, we predicted mood after imagination (T4) with mood before imagination (T3) and tested again whether experimental condition explained additional variance. We repeated these analyzes for BIS.

To test whether ED symptomatology moderates the effect of experimental condition after imagination, we entered the normalized and centered EDE-Q score (lnEDE-Q = natural 
logarithm of $(E D E-Q+0.5)-0.23)$ in a third step, and then tested in a final step whether the interaction of $\operatorname{lnEDE}-\mathrm{Q}$ and experimental condition explained additional variance. We proceeded in the same way to explore whether BMI (mean centered) moderates the effect of experimental condition after imagination.

To test whether TSF-B differed between the two groups, we applied a Mann-WhitneyU-Test, because this variable was severely skewed. We therefore normalized TSF-B for the moderator analyzes $(\operatorname{lnTSF}-\mathrm{B}=$ natural logarithm $(\mathrm{TSF}-\mathrm{B}+0.1))$.

Due to an administrative error, responses of five participants were not recorded at $\mathrm{T} 1$. Assuming that non-recorded data were missing at random, we used multiple imputation to estimate those missing data (for further information see appendix B).

We conducted sensitivity analyses with G*Power 3.1.7 (Faul, Erdfelder, Buchner, \& Lang, 2009) before we analyzed the data. For the repeated measures analysis of variance, power was sufficient (.80, alpha .05$)$ to detect medium between subject effects $(f=0.26)$, and small within subject and interaction effects $(f=0.10)$, when a correlation between repeated measures of rho .7 was assumed. Regarding multiple regression analyses, power was sufficient (.80, alpha .05$)$, to detect moderate to large increases in the remaining variance, when a single predictor was added to the equation $\left(f^{2}=0.09\right)$.

\section{RESULTS}

\subsection{Participant characteristics}

Participating women were between $18-30$ years old $(M=21.9, S D=2.0)$ and had a BMI between $16.8-30.0(M=21.7, S D=2.4)$. A total of $6.6 \%$ of the participants were underweight $(\mathrm{BMI}<18.5)$ and $5.5 \%$ were overweight $(\mathrm{BMI}>25)$. The mean EDE-Q total score was 0.92 $(S D=0.74)$ and $2.2 \%$ of the participants reported elevated ED symptomatology (defined by an EDE-Q total score > 2.66, as in Hilbert et al., 2007).

3.2. Effects of experimental manipulations on mood, BIS, and TSF-B 
Regarding mood, the ANOVA revealed that there was no significant main effect of experimental condition $\left(F(1,89)=3.71, p=.057, \eta_{p}{ }^{2}=.040\right),{ }^{2}$ but a large and significant main effect of time $\left(F(2.67,238.93)=18.54, p<.001, \eta_{p}{ }^{2}=.175\right)$, and a moderate and significant interaction effect of time by condition $\left(F(2.67,238.93)=9.19, p<.001, \eta_{p}{ }^{2}=\right.$ .092). Figure 1 shows that mood equally improved in both groups from T1 to T3, further improved from T3 to T4 in the control group but decreased in the thin-ideal group. This pattern of means suggests that only the imagination of thin ideals induced a decrease in mood, and supports our hypothesis. Regarding BIS, results were quite similar (figure 2). There was no significant main effect of condition $\left(F(1,89)=0.23 p=.635, \eta_{p}{ }^{2}=.003\right)$ but, a large and significant main effect of time $\left(F(2.86,254.49)=31.91, p<.001, \eta_{p}{ }^{2}=.264\right)$, and a moderate and significant interaction effect of time by condition $\left(F(2.86,254.49)=10.09, p<.001, \eta_{p}{ }^{2}\right.$ $=.102)$.

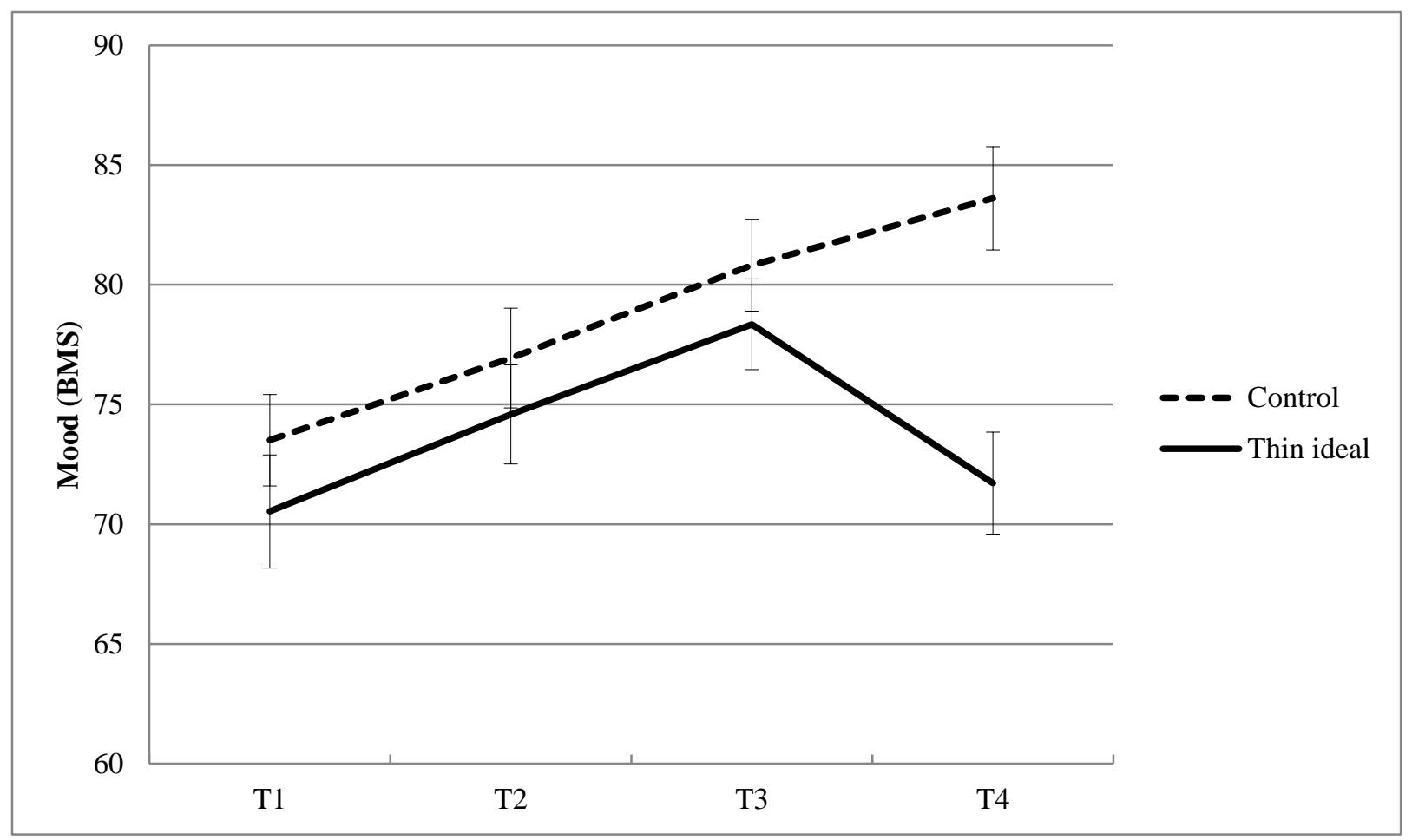

FIGURE 1: Changes in mood from T1 to T4 (means and standard errors).

Notes: control=control group $(\mathrm{n}=45)$; thin ideal=thin-ideal group $(\mathrm{n}=46) ; \mathrm{T} 2=$ after media exposure, $\mathrm{T} 4=\mathrm{after}$ vivid imagination. 


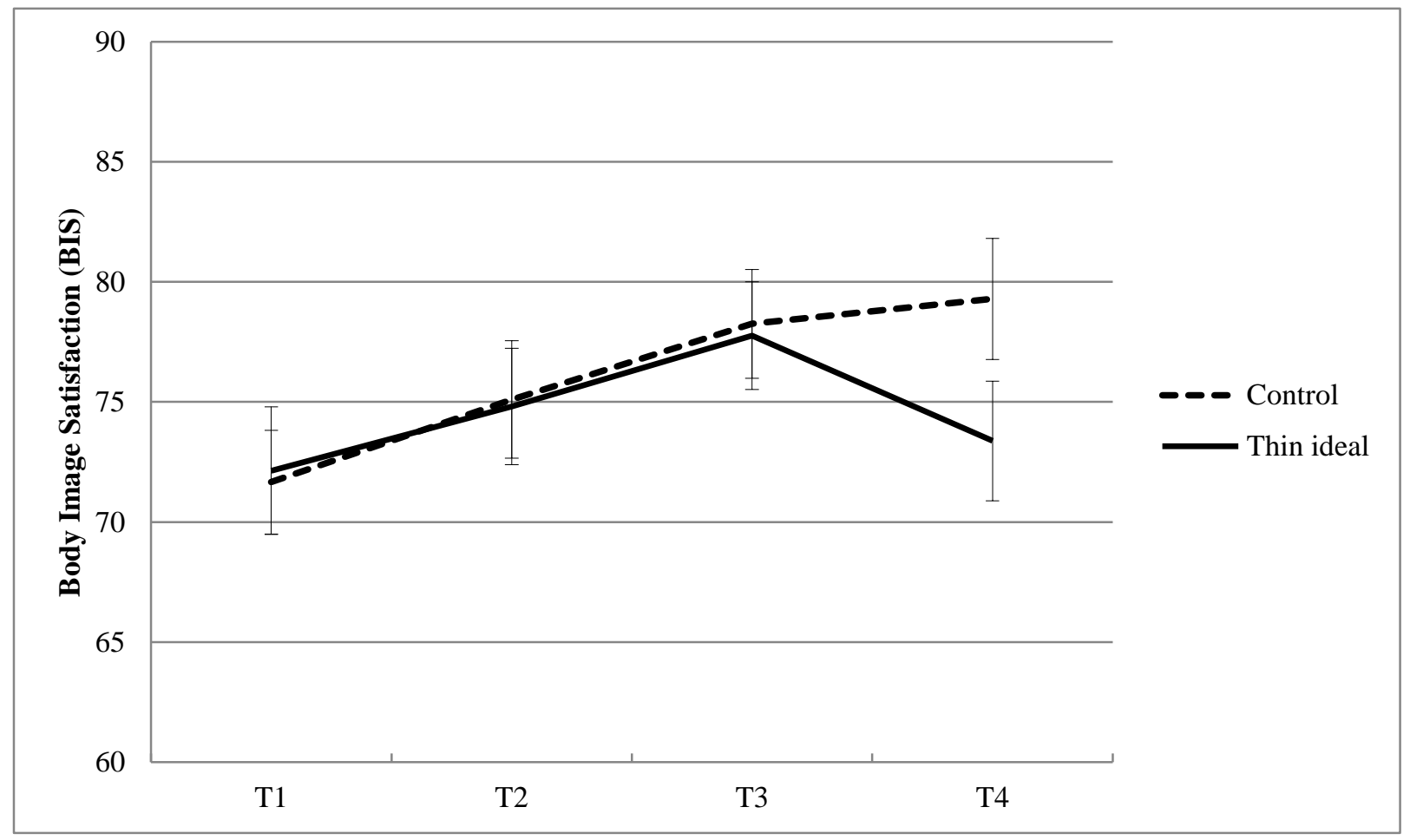

FIGURE 2: Changes in body image satisfaction (BIS) from T1 to T4 (means and standard errors).

Notes: control=control group $(\mathrm{n}=45)$; thin ideal=thin-ideal group $(\mathrm{n}=46) ; \mathrm{T} 2=$ after media exposure, $\mathrm{T} 4=\mathrm{after}$ vivid imagination.

Focused statistical tests with multiple linear regression analyses are in line with the results given above. After magazine exposure (T2), experimental groups were neither different in mood $\left(R_{\text {Change }}^{2}<.001, F(1,88)=0.02, p=.897\right)$ nor BIS $\left(R_{\text {Change }}^{2}<.001, F(1,88)\right.$ $=0.49, p=.487$, when mood or BIS before magazine exposure (T1) had been controlled in the first step $\left(R_{\text {Change }}^{2}\right.$ in mood $=.561, F(1,89)=113.79, p<.001 ; R_{\text {Change }}^{2}$ in BIS $=.914, F(1$, $89)=947.19, p<.001)$. However, experimental condition explained $10 \%$ of the variation in mood after imagination (T4) $\left(R_{\text {Change }}^{2}=.099, F(1,88)=23.67, p<.001\right)$, when controlling for mood before imagination (T3) $\left(R_{\text {Change }}^{2}=.531, F(1,89)=100.78, p<.001\right)$. The regression coefficient of experimental condition was $B=-9.80(\mathrm{SE}=2.02, \beta=-.32, p<$ .001). This finding supports our hypothesis, and demonstrates that mood of participants who 
imagined thin ideals decreased almost 10 points below mood of participants who imagined landscapes. For BIS, the pattern of results was the same as for mood. However, BIS at T3 explained a larger amount of variation in BIS at T4 $\left(R_{\text {Change }}^{2}=.818, F(1,89)=398.78\right.$, $p<.001)$, and the effect of experimental condition - although statistically significant - was rather small $\left(R_{\text {Change }}^{2}=.025, F(1,88)=14.28, p<.001\right)$. The regression coefficient of experimental condition $(B=-5.18, \mathrm{SE}=1.43, \beta=-.16, p<.001)$ indicates that compared to participants who imagined landscapes, BIS of participants who imagined thin ideals decreased about 5 points.

Finally, the Mann-Whitney-U-test revealed that TSF-B assessed after imagination was significantly higher $(U=475.50, p<.001)$ in the thin-ideal group $(M=16.80, S D=18.53$, Median=10.10) than in the control group $(M=3.76, S D=7.02$, Median=1.40). This supports the conclusion that our experimental manipulation activated the expected body-related cognitive distortions.

3.3. ED symptomatology and BMI as moderating variables

We expected that negative effects of the imagination of thin ideals are larger for those women who reported higher ED symptomatology. Regarding BIS after imagination, neither the lnEDE-Q score explained additional variance $\left(R_{\text {Change }}^{2}=.002, F(1,87)=1.04, p=.310\right)$, nor its interaction with experimental condition $\left(R_{\text {Change }}^{2}=.001, F(1,86)=0.40, p=.529\right)$. However, ED symptomatology explained a small to moderate additional part of the variance in mood after imagination $\left(R_{\text {Change }}^{2}=.047, F(1,87)=12.63, p=.001\right)$ as did the interaction of $\operatorname{lnEDE}-\mathrm{Q}$ with experimental condition $\left(R_{\text {Change }}^{2}=.049, F(1,86)=15.30, p<.001\right)$. Using regression coefficients of the final model, ${ }^{3}$ we computed the predicted outcome values, which showed that EDE-Q raw scores moderate the effect of experimental condition on mood after imagination, given that mood before imagination was at the average. In $\operatorname{lnTSF}-\mathrm{B}, \operatorname{lnEDE}-\mathrm{Q}$ explained a moderate amount of additional variance $\left(R_{\text {Change }}^{2}=.129, F(1,88)=17.52\right.$, $p<.001),{ }^{4}$ as did the product of the lnEDE-Q with experimental condition $\left(R^{2}\right.$ Change $=.067$, 
$F(1,87)=10.09, p=.002) .{ }^{5}$ Figure 3 shows how EDE-Q raw scores moderate the effect of experimental condition on TSF-B raw scores.

BMI did not explain additional variance in mood after imagination, when mood before imagination and experimental condition were already controlled $\left(R_{\text {Change }}^{2}=.002, F(1,87)=\right.$ $0.44, p=.508)$. BMI did not explain additional variance in BIS $\left(R^{2}\right.$ Change $=.005, F(1,87)=$ $2.64, p=.108)$, nor in $\operatorname{lnTSF}-\mathrm{B}\left(R_{\text {Change }}^{2}=.003, F(1,88)=0.36, p=.551\right)$. Moreover, there was no interaction effect of BMI and experimental condition on $\operatorname{mood}\left(R^{2}\right.$ Change $<.001, F(1$, $86)=0.02, p=.932), \mathrm{BIS}\left(R_{\text {Change }}^{2}=.006, F(1,86)=3.47, p=.068\right)$, or lnTSF-B $\left(R_{\text {Change }}^{2}=\right.$ $.015, F(1,87)=1.72, p=.194)$.

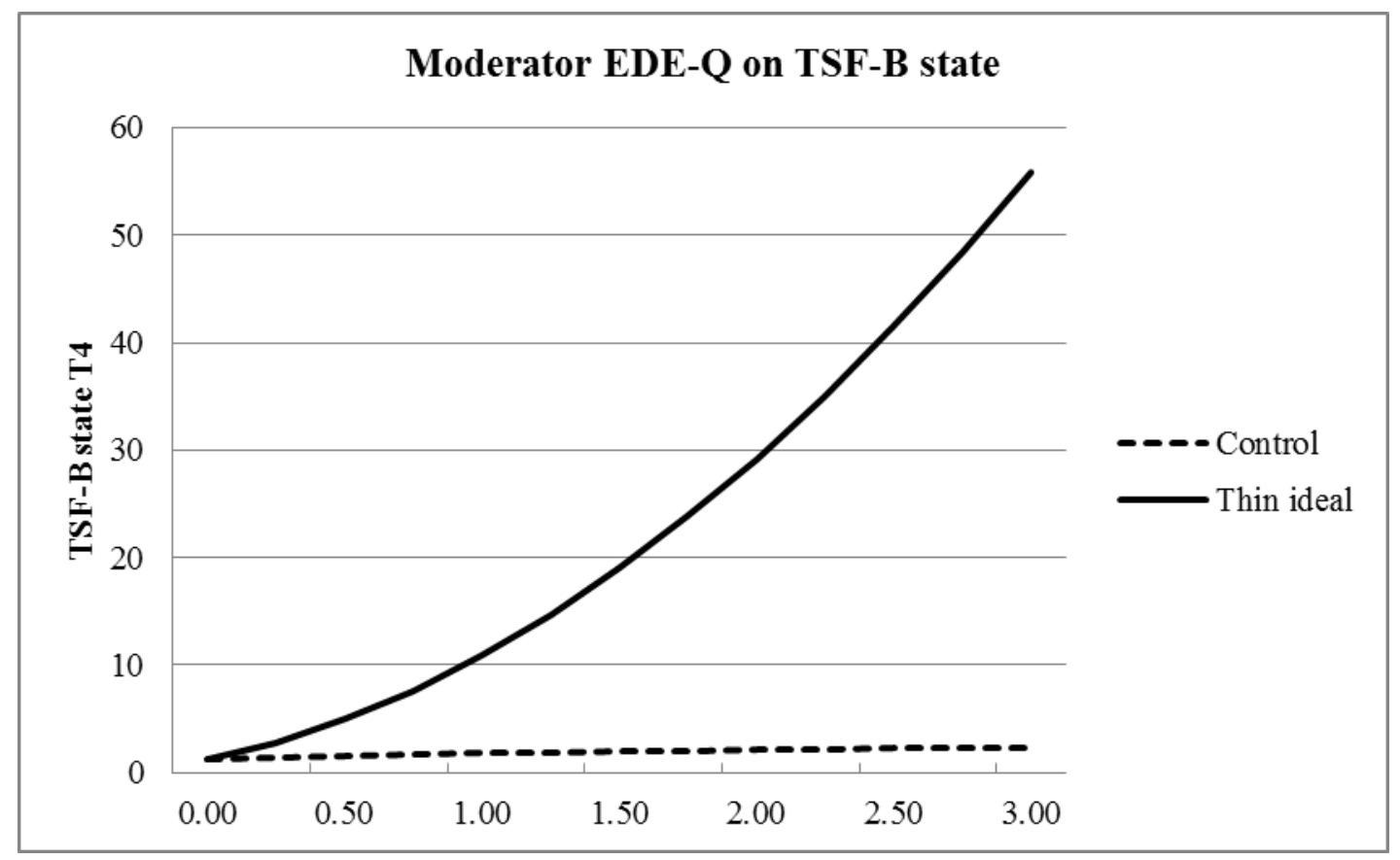

FIGURE 3: Moderating effect of ED symptomatology on changes in TSF-B state after vivid imagination.

Notes: control=control group $(n=45)$; thin ideal=thin-ideal group $(n=46)$. On the $\mathrm{x}$-axis EDE-Q raw scores are displayed. 


\section{DISCUSSION}

The present study aimed at investigating whether vivid imagination of thin ideals after media exposure leads to activation of body-related cognitive distortions as well as to a decrease in mood and BIS in healthy young women. Additionally, we expected that imagination of thin ideals would lead to more pronounced effects in women with symptoms of disordered eating and in women with higher BMI (Ferguson, 2013; López-Guimerà et al., 2010; Stice \& Whitenton, 2002).

Our results suggest that a short media exposure to a fashion magazine in a waiting room did not influence mood or BIS. This finding is in contrast to Turner and colleagues (1997), who reported decreased BIS, more preoccupation with the desire to be thin, and more fear of weight gain in healthy undergraduate women after exposure to fashion magazines compared to nature magazines. Our results indicate a continuous recovery during the stay in the laboratory, i.e. an increase in positive mood and thus no effect of media exposure in the waiting room. The divergent results may be due to different age ranges in the two studies (mean age of 18.6 years compared to 21.9 years in our sample). Moreover, (Turner et al., 1997) did not take into account BIS before media exposure. Finally, an increased availability of media nowadays may have decreased the sensitivity towards low intensity exposure (as with magazines in a waiting room) in young healthy women.

As hypothesized, our results reveal that body-related cognitive distortions (TSF-B) in terms of perception of weight gain, fatness and moral wrongdoing were activated through vivid imagination of thin ideals seen in a magazine (but not after imagining landscapes). Moreover, self-reported urges to restrict food intake were evoked, which could foster later ED relevant behavior. However, the specific behavioral consequences resulting from thin-ideal imagination, and the conditions in which these behaviors are evoked, require further research. Additionally, it remains to be investigated if the immediate responsiveness to thin-ideal imagination in terms of the activation of body-related cognitive distortions represents a 
marker for a certain susceptibility and whether a cumulative negative effect on mood, BIS and dysfunctional eating is observable.

Simultaneously with the activation of TSF-B, participants, who were instructed to imagine thin ideals, experienced a significant decline in mood and BIS. In contrast, in participants imagining landscapes, mood and BIS values continued to improve. It can be concluded that in our study, mere magazine exposure did not impair psychological well-being on the short-term, whereas the subsequent intensified imagination of thin ideals had negative effects. Moreover, changes in mood and BIS occurred simultaneously with the activation of cognitive distortions (TSF-B) after vivid imagination, and thus seem to be related. However, it remains unclear whether these specific cognitive distortions mediate changes in mood and BIS or whether the chronology is rather vice versa.

As mentioned, we did not find mere magazine exposure to have an influence on participant's mood and BIS. In order to find out whether mere imagination of thin-ideals without prior media exposure leads to comparable effects, future studies should include a mere exposure, a mere imagination and a combined condition. Such a manipulation will allow specifying the importance of cognitive factors such as TSF-B alone and in combination with an exposure to thin ideals in fashion magazines in certain individuals. Moreover, such a design will allow differentiating between the characteristics of individuals affected already if solely media exposure or solely imagination is triggered and those, who are affected, if both conditions (exposure to and imagination of thin ideals) are presented.

As assumed, the effect of vivid imagination was influenced by ED symptomatology: Whereas in women imagining landscapes, ED symptomatology did not influence mood, in women imagining thin ideals, mood decreased only if they were characterized by more pronounced ED symptomatology (average (0.91) to high (> 2.66) ED raw score; Hilbert et al., 2007). In women without relevant ED symptomatology (EDE-Q raw scores < .25), mood was comparable, independently whether imagining landscapes or thin ideals. Moreover, women 
with more pronounced ED symptomatology identified themselves more strongly with statements that refer to cognitive distortions such as feelings of fatness, weight gain and moral wrongdoing (according to the TSF-B state questionnaire) after thin-ideal imagination. Cognitive distortions increased exponentially with the reported severity of the ED symptomatology. No such moderating effect was found for BIS. Generally, compared to measures of mood, self-report measures of BIS were lesser affected by the experimental manipulation in our study. This might be explained by the fact that unlike mood, BIS represents a relatively stable construct, probably not susceptible to an immediate change.

To conclude, the activation of cognitive distortions such as TSF-B (imagination of thin ideals) as well as the original TSF (imagination of fattening/ forbidden food; e.g., Coelho, Baeyens, et al., 2012) in young healthy women seems to depend on the degree of ED symptomatology. This preexisting factor influences mood and TSF-B in addition to the single application of an experimental manipulation such as ours (which is in line with previous studies; for an overview see Ferguson, 2013). Repeated exposure to thin ideals as it happens in daily life (Hargreaves \& Tiggemann, 2003) together with a susceptibility to body-related cognitive distortions may be relevant factors in predicting long-term negative effects. Future longitudinal and intervention studies should investigate whether the susceptibility to TSF-B represents a potential risk factor for later ED development and whether TSF-B can be modified (Coelho et al., 2014).

In our sample, BMI did not influence the effect of vivid thin-ideal imagination after media exposure. This could be explained by the fact that most of the young females in our sample were of normal weight. Reevaluating the role of BMI in a larger sample of overweight, obese or underweight women could reveal differential responses to the exposure with thin ideals. A prior study using the original, food exposure related TSF paradigm revealed a more pronounced susceptibility in normal weight compared to overweight females (Coelho, Jansen, \& Bouvard, 2012). 
Our findings have to be interpreted by taking several limitations into account. First, as we investigated a group of young healthy females, our findings cannot be generalized to samples with obesity, EDs or males. Secondly, we assessed BIS by a self-developed visual analogue scale. We therefore cannot rule out if impaired reliability or validity of our instrument and not the stability of the body image construct prevented us from finding more pronounced BIS changes during the experiment. Thirdly, the study design was in favor of ecological validity, accepting limitations to internal validity. In other words, we asked our participants, to look at the magazines, but did not manipulate the duration or intensity of the exposure nor did we verify the exposure by eye-tracking participants while looking at the pictures in the magazine. Additionally, we only asked the participants not to inform other participants about the procedure during the experiment, but cannot guarantee that the content of the study was not disclosed. Finally, findings of this study rely exclusively on self-report; behavioral observation measures such as monitoring body checking or eating behavior should be added.

Despite these limitations, the results of the present study revealed that the vivid imagination of thin ideals is accompanied by a decrease in mood and BIS and triggers bodyrelated cognitive distortions such as TSF-B. Regarding the decrease in mood and BIS, the results showed that imagination of thin ideals, rather than mere exposure to a fashion magazine, has a negative impact. Thus, the cognitive processing of daily thin-ideal exposure (such as imagining) could represent another potential key to the risk of ED pathology and should be further investigated. This is even more important, as cognitive distortions are known to be related to emotional and behavioral consequences (e.g., in anxiety or depressive disorders; Beck, 1963) and might provoke negative mood, BD and dysfunctional eating behavior, especially in women characterized by a higher level of ED symptomatology. It might further be expected that similar processes occur when young women exchange their views and experiences on what they have seen in model casting shows or in fashion 
magazines in everyday situations. Using real-time assessment methods in futures studies is a promising approach in order to achieve a more precise understanding of body-related cognitive distortions such as TSF-B (e.g., Leahey, Crowther, \& Ciesla, 2011). In sum, TSF-B could be a factor that ranks among other explanations for the stronger or lower susceptibility to the negative influence of thin ideals transmitted via media. A deeper understanding of such mechanisms fosters future prevention and treatment efforts. 


\section{ACKNOWLEDGEMENTS AND AUTHOR NOTES}

This study was supported by grants from the Research Fund of the University of Fribourg, Switzerland (Grant Number 419), the Swiss Anorexia Nervosa Foundation (Grant Number 22-12) and the Swiss National Science Foundation (Grant Number 100014L_149416/1).

We thank Ian Law for proof reading the article.

Jennifer Coelho moved to a new position during the course of this research. She is currently at the Provincial Specialized Eating Disorders Program for Children \& Adolescents, BC Children's Hospital, Canada. 
APPENDIX A: Items of the Thought-Shape Fusion Body State Scale (TSF-B state)

TSF-B state

\section{Item 1}

GE: Haben Sie das Gefühl, dass Sie an Gewicht zugenommen haben, nachdem Sie sich die Bilder aus der Zeitschrift vorgestellt haben?

EN: Do you experience a feeling of weight gain after imagining the pictures from the magazine?

\section{Item 2}

GE: Wie viel dicker fühlen Sie sich nachdem Sie sich die Bilder aus der Zeitschrift vorgestellt haben?

EN: How much fatter do you feel right now after imagining the pictures from the magazine?

Item 3

GE: In welchem Ausmass war es moralisch anstössig, dass Sie sich die Bilder aus der Zeitschrift vorgestellt haben?

EN: How morally wrong was it to imagine the pictures from the magazine?

\section{Item 4}

GE: In welchem Ausmass haben Sie den Drang, die Auswirkungen, die sich durch das Vorstellen der Bilder aus den Zeitschriften ergeben haben, zu reduzieren oder rückgängig zu machen?

EN: To what extent do you have an urge to reduce or eliminate the effects of imagining the pictures from the magazine?

\section{Item 5}

GE: In welchem Ausmass haben Sie im Moment den Drang, Ihre Nahrungsaufnahme einzuschränken (z.B. während der nächsten paar Stunden gar nichts zu essen/ zu fasten) weil Sie sich die Bilder aus der Zeitschrift vorgestellt haben?

EN: To what extent do you have an urge to restrict your food intake right now (e.g., to avoid eating for several hours/ to fast) due to imagining the pictures from the magazine?

Notes: $\mathrm{GE}=$ German version; $\mathrm{EN}=$ English translation; participants answered each item on a visual analog scale (0 not at all to 100 completely). 
APPENDIX B: Further information regarding multiple imputation to estimate missing data

We used the fully conditional specification (FCS) procedure, implemented in SPSS 22, which is based on an iterative Markov chain Monte Carlo (MCMC) method that does not make assumptions about the distribution of variables. Applying multiple linear regression the five missing cases $(5.5 \%)$ in mood and BIS at T1 were simultaneously predicted by mood and BIS assessed at T2, T3, T4 (that were highly correlated with T1), and all variables used in the regression models, described above. Inspecting the plots of the FCS iteration history data, we ensured that 10 iterations were sufficient to achieve stable estimates for each of the 20 imputed data sets generated by the program. Inspection of the imputed data revealed that none of the estimated values was above the maximum or below the minimum of the original data. Statistical analyses described above were then conducted separately for each of the 20 imputed data sets and the original data with listwise missing.

SPSS provides results pooled across the imputed samples for means and regression coefficients, corresponding standard errors and t-tests. However, for $F$-tests and the corresponding effect sizes $\left(\eta_{p}{ }^{2}\right.$ or $R^{2}$-change) it does not. Although, recently van Ginkel \& Kroonenberg (2014) reported a method to pool $F$-tests across imputed datasets, this method is complicated and requires a lot of extra computational effort. Moreover, it does not take adjustments due to the violation of the sphericity assumptions into account. Therefore, we reported the median of test results $\left(F\right.$-values, Huynh-Feldt adjusted df, $\eta_{p}{ }^{2}$ for analyses of variance and $R^{2}$-change and corresponding $F$-values for the regression models to predict T2) for the 20 imputed samples and add a footnote if in any of the 20 imputed data sets or in the original data with listwise missing, test results would suggest a different interpretation - which was only once the case. 


\section{REFERENCES}

APA. (2000). Diagnostic and statistical manual of mental disorders: DSM-IV-TR (4th ed.). Washington D.C.: American Psychiatric Association.

Beck, A. T. (1963). Thinking and Depression. I. Idiosyncratic Content and Cognitive Distortions. Arch Gen Psychiatry, 9, 324-333. doi: 10.1001/archpsyc.1963.01720160014002

Coelho, J. S., Baeyens, C., Purdon, C., Pitet, A., \& Bouvard, M. (2012). Cognitive distortions and eating pathology: Specificity of thought-shape fusion. Behaviour Research and Therapy, 50(7), 449-456. doi: 10.1016/j.brat.2012.04.003

Coelho, J. S., Carter, J. C., McFarlane, T., \& Polivy, J. (2008). "Just looking at food makes me gain weight": experimental induction of thought-shape fusion in eating-disordered and non-eating-disordered women. Behaviour Research and Therapy, 46(2), 219-228. doi: 10.1016/j.brat.2007.11.004

Coelho, J. S., Jansen, A., \& Bouvard, M. (2012). Cognitive Distortions in Normal-Weight and Overweight Women: Susceptibility to Thought-Shape Fusion. Cognitive Therapy and Research, 36(4), 417-425. doi: 10.1007/s10608-011-9372-0

Coelho, J. S., Roefs, A., \& Jansen, A. (2010). The role of food-cue exposure and negative affect in the experience of thought-shape fusion. Journal of Behavior Therapy and Experimental Psychiatry, 41(4), 409-417. doi: 10.1016/j.jbtep.2010.04.004 
Coelho, J. S., Wilson, S., Winslade, A., Thaler, L., Israel, M., \& Steiger, H. (2014). Over-evaluation of thoughts about food: Differences across eating-disorder subtypes and a preliminary examination of treatment effects. International Journal of Eating Disorders, 47(3), 302-309. doi: 10.1002/eat.22207

Cooper, M. J., \& Fairburn, C. G. (1992). Thoughts about eating, weight and shape in anorexia nervosa and bulimia nervosa. Behaviour Research and Therapy, 30, 501-511. doi: 10.1016/0005-7967(92)90034-E

Dittmar, H., Halliwell, E., \& Stirling, E. (2009). Understanding the impact of thin media models on women's body-focused affect: The roles of thin-ideal internalization and weight-related self-discrepancy activation in experimental exposure effects. Journal of Social and Clinical Psychology, 28(1), 43-72. doi: 10.1521/jscp.2009.28.1.43

Dittmar, H., \& Howard, S. (2004). Ideal-body internalization and social comparison tendency as moderators of thin media models' impact on women's body-focused anxiety. Journal of Social and Clinical Psychology, 23, 768-791. doi: $10.1521 /$ jscp.23.6.768.54799

Fairburn, C. G. (1981). A cognitive behavioural approach to the treatment of bulimia. Psychol Med, 11(4), 707-711. doi: 10.1017/S0033291700041209

Fairburn, C. G., Cooper, Z., \& Shafran, R. (2003). Cognitive behaviour therapy for eating disorders: A "transdiagnostic" theory and treatment. Behaviour Research and Therapy, 41(5), 509-528. doi: 10.1016/S0005-7967(02)00088-8 
Faul, F., Erdfelder, E., Buchner, A., \& Lang, A. G. (2009). Statistical power analyses using G* Power 3.1: Tests for correlation and regression analyses. Behavior Research Methods, 41(4), 1149-1160. doi: 10.3758/BRM.41.4.1149

Ferguson, C. J. (2013). In the eye of the beholder: Thin-ideal media affects some, but not most, viewers in a meta-analytic review of body dissatisfaction in women and men. Psychology of Popular Media Culture, 2(1), 20-37. doi: 10.1037/a0030766

Fiske, L., Fallon, E. A., Blissmer, B., \& Redding, C. A. (2014). Prevalence of body dissatisfaction among United States adults: review and recommendations for future research. Eating Behaviors, 15(3), 357-365. doi: 10.1016/j.eatbeh.2014.04.010

Grogan, S. (2008). Body image: understanding body dissatisfaction in men, women, and children. (second edition ed.). London; New York: Routledge.

Hargreaves, D., \& Tiggemann, M. (2003). Longer-Term Implications of Responsiveness to 'Thin-Ideal' Television: Support for a Cumulative Hypothesis of Body Image Disturbance? European Eating Disorders Review, 11, 465-477. doi: 10.1002/erv.509

Hausenblas, H. A., Campbell, A., Menzel, J. E., Doughty, J., Levine, M., \& Thompson, J. K. (2013). Media effects of experimental presentation of the ideal physique on eating disorder symptoms: a meta-analysis of laboratory studies. Clin Psychol Rev, 33(1), 168-181. doi: 10.1016/j.cpr.2012.10.011

Higgins, E. T. (1987). Self-discrepancy: a theory relating self and affect. Psychological review, 94(3), 319. 
Hilbert, A., \& Tuschen-Caffier, B. (2006). Eating Disorder Examination-Questionnaire: Deutschsprachige Übersetzung. Münster: Verlag für Psychotherapie.

Hilbert, A., Tuschen-Caffier, B., Karwautz, A., Niederhofer, H., \& Munsch, S. (2007). Eating Disorder Examination-Questionnaire. Evaluation der deutschsprachigen Übersetzung. Diagnostica, 53(3), 144-154.

Leahey, T. M., Crowther, J. H., \& Ciesla, J. A. (2011). An ecological momentary assessment of the effects of weight and shape social comparisons on women with eating pathology, high body dissatisfaction, and low body dissatisfaction. Behav Ther, 42(2), 197-210. doi: 10.1016/j.beth.2010.07.003

Levine, M. P., \& Murnen, S. K. (2009). "Everybody knows that mass media are/are not [pick one] a cause of eating disorders": A critical review of evidence for a causal link between media, negative body image, and disordered eating in females. Journal of Social and Clinical Psychology, 28(1), 9-42. doi: 10.1521/jscp.2009.28.1.9

López-Guimerà, G., Levine, M. P., Sánchez-Carracedo, D., \& Fauquet, J. (2010). Influence of mass media on body image and eating disordered attitudes and behaviors in females: A review of effects and processes. Media Psychology, 13(4), 387-416. doi: $10.1080 / 15213269.2010 .525737$

Mond, J. M., Hay, P. J., Rodgers, B., Owen, C., \& Beumont, P. J. (2004). Validity of the Eating Disorder Examination Questionnaire (EDE-Q) in screening for eating disorders in community samples. Behaviour Research and Therapy, 42(5), 551-567. doi: 10.1016/S0005-7967(03)00161-X 
Munsch, S. (2014). Study protocol: psychological and physiological consequences of exposure to mass media in young women - an experimental cross-sectional and longitudinal study and the role of moderators. BMC Psychology, 2(1), 37. doi: $10.1186 / \mathrm{s} 40359-014-0037-0$

Myers, T. A., \& Crowther, J. H. (2009). Social comparison as a predictor of body dissatisfaction: A meta-analytic review. Journal of Abnormal Psychology, 118(4), 683. doi: $10.1037 / \mathrm{a} 0016763$

Radomsky, A. S., De Silva, P., Todd, G., Treasure, J., \& Murphy, T. (2002). Thought-shape fusion in anorexia nervosa: An experimental investigation. Behaviour Research and Therapy, 40(10), 1169-1177. doi: 10.1016/S0005-7967(01)00085-7

Ridolfi, D. R., Myers, T. A., Crowther, J. H., \& Ciesla, J. A. (2011). Do appearance focused cognitive distortions moderate the relationship between social comparisons to peers and media images and body image disturbance? Sex Roles, 65(7-8), 491-505. doi: $10.1007 / \mathrm{s} 11199-011-9961-0$

Rohde, P., Lewinsohn, P. M., \& Seeley, J. R. (2014). Comparability of telephone and face-toface interviews in assessing axis I and II disorders. The American Journal of Psychiatry, 154(11), 1593-1598. doi: 10.1176/ajp.154.11.1593

Schneider, S., \& Margraf, J. (2011). DIPS: Diagnostisches Interview Bei Psychischen Störungen Handbuch-Interviewleitfaden-Protokollbogen. Berlin: Springer Verlag. 
Shafran, R., \& Robinson, P. (2004). Thought-shape fusion in eating disorders. British Journal of Clinical Psychology, 43(4), 399-408. doi: 10.1348/0144665042389008

Shafran, R., Teachman, B. A., Kerry, S., \& Rachman, S. (1999). A cognitive distortion associated with eating disorders: Thought-shape fusion. British Journal of Clinical Psychology, 38(2), 167-179. doi: 10.1348/014466599162728

Shafran, R., Thordarson, D. S., \& Rachman, S. (1996). Thought-action fusion in obsessive compulsive disorder. Journal of Anxiety Disorders, 10(5), 379-391. doi: $10.1016 / 0887-6185(96) 00018-7$

Stice, E., Marti, C. N., \& Durant, S. (2011). Risk factors for onset of eating disorders: Evidence of multiple risk pathways from an 8-year prospective study. Behaviour Research and Therapy, 49(10), 622-627. doi: 10.1016/j.brat.2011.06.009

Stice, E., \& Whitenton, K. (2002). Risk factors for body dissatisfaction in adolescent girls: a longitudinal investigation. Dev Psychol, 38(5), 669-678. doi: 10.1037/00121649.38.5.669

Swami, V., Frederick, D. A., Aavik, T., Alcalay, L., Allik, J., Anderson, D., . . Cunningham, J. (2010). The attractive female body weight and female body dissatisfaction in 26 countries across 10 world regions: Results of the International Body Project I. Personality and social psychology bulletin, 36(3), 309-325. doi: $10.1177 / 0146167209359702$ 
Tiggemann, M. (2002). Media influences on body image development. In T. F. Cash \& T. Pruzinsky (Eds.), Body image: A handbook of theory, research, and clinical practice. (pp. 91-98). New York: Guilford Press.

Tiggemann, M., \& McGill, B. (2004). The role of social comparison in the effect of magazine advertisements on women's mood and body dissatisfaction. Journal of Social and Clinical Psychology, 23(1), 23-44. doi: 10.1521/jscp.23.1.23.26991

Turner, S. L., Hamilton, H., Jacobs, M., Angood, L. M., \& Dwyer, D. H. (1997). The influence of fashion magazines on the body image satisfaction of college women: an exploratory analysis. Adolescence, 603-614.

van Ginkel, J. R., \& Kroonenberg, P. M. (2014). Analysis of Variance of Multiply Imputed Data. Multivariate Behav Res, 49(1), 78-91. doi: 10.1080/00273171.2013.855890

Wilhelm, P., \& Schoebi, D. (2007). Assessing mood in daily life: Structural validity, sensitivity to change, and reliability of a short-scale to measure three basic dimensions of mood. European Journal of Psychological Assessment, 23(4), 258. doi: $10.1027 / 1015-5759.23 .4 .258$ 


\section{FOOTNOTES}

${ }^{1}$ In a pre-test ( $\mathrm{N}=45$ healthy participants) no effect of the film was demonstrated on "serenity" and "seriousness" ( $p>.33)$, thought there was a slight reduction of "bad mood" $(p<.01)$

${ }^{2}$ In two of the 20 repeated analyses the main effect of experimental condition was significant $\left(F(1,89) \geq 4.00, p \leq .049, \eta_{p}^{2} \geq .043\right)$.

${ }^{3}$ Coefficients of the final moderator model that predicted mood were as follows: Constant: $\quad B=82.32 ; S E=1.25 ; \quad$ Mood $\quad$ T3: $\quad B=0.81 ; S E=.07, \beta=.67, p<.001 ; \quad$ experimental condition: $\quad B=-10.12, S E=1.76, \beta=-.33, p<.001 ; \quad \operatorname{lnEDE}-\mathrm{Q}: \quad B=.17, S E=2.51, \beta=.01, p=.947$; interaction of experimental condition and lnEDE-Q: $B=-13.93, S E=3.56,=-.31, p<.001$ ).

${ }^{4}$ Experimental condition, entered as the first predictor, explained 22 percent of the variation $(F(1,89)=25.38, p<.001)$.

${ }^{5}$ Coefficients of the final moderator model that predicted lnTSF-B were as follows: Constant: $B=0.58 ; S E=0.18$; experimental condition: $B=1.48, S E=0.25, \beta=.48, p<.001 ; \ln E D E-$ Q: $B=0.31, S E=0.36, \beta=.10, p=.393$; interaction of experimental condition and lnEDE-Q: $B=1.61, S E=0.51, \beta=.37, p=.002)$. 